\title{
Early Experience of New Oral Anticoagulants for Stroke Prevention in Octogenarian Patients with Atrial Fibrillation
}

Gi-Byoung Nam, MD ${ }^{1}$, Min Su Kim $M D^{1}$, Chang Hee Kwon, $M^{2}$

${ }^{1}$ Heart Institute, Asan Medical Center

Department of Internal Medicine, University of Ulsan College of Medicine, Seoul, Korea

${ }^{2}$ Division of Cardiology, Konkuk University Medical Center, Konkuk University School of Medicine, Seoul, Korea.
Received: August 17, 2015

Revision Received: November 13, 2015

Accepted: December 15, 2015

Correspondence: Gi-Byoung Nam, MD, PhD

Heart Institute, Asan Medical Center, 43 Olympic-

Ro, Songpa-Gu, Seoul, Republic of Korea, 138-736

Phone: +82-2-3010-3159, Fax: +82-2-486-5918

E-mail: gbnam@amc.seoul.kr

Copyright (C) 2015 The Official Journal of Korean Heart

Rhythm Society Editorial Board \& MMK Co., Ltd.

\begin{abstract}
Background and Objectives: The safety of new oral anticoagulants (NOACs) depends largely on renal function. As renal function deteriorates with aging, the safety of NOACs is clinically important for very old cardiac patients. This study analyzed the efficacy and safety of NOACs prescribed to an octogenarian population in a university hospital.
\end{abstract}

Subject and Methods: A total of 158 consecutive patients aged $\geq 80$ years and who had been prescribed NOACs for non-valvular atrial fibrillation (54 patients on dabigatran, 104 patients on rivaroxaban) were included. Demographic features, laboratory findings, and clinical follow-up results were retrospectively reviewed.

Results: Reduced doses were prescribed in 105 (66.2\%) patients. The estimated GFR curve in octogenarian patients shifted left compared to that of patients aged $<80$ years. There were two strokes or systemic embolic events during the follow-up period of 276 days. Major bleeding occurred in 13 patients, where gastrointestinal bleeding and anemia of unknown origin were the major causes.

Conclusion: NOACs seem to be highly effective for the prevention of stroke or systemic embolism in octogenarian populations. Bleeding events occurred in a considerable number of the study patients. Further studies on optimum dose ranges are required for very old subjects.

Key Words: - Atrial Fibrillation -Stroke - Embolism - Bleeding - Anticoagulants

\section{Introduction}

The prevalence of atrial fibrillation (AF) and AF-related stroke events have been shown to increase with age..$^{1-6}$ Anticoagulation using warfarin is effective for the prevention of stroke or systemic embolic events. However, warfarin requires periodic blood monitoring and interacts with numerous drugs and food; thus, it is underutilized in elderly patients for fear of a higher risk of 
bleeding and poor tolerability.7 Unlike warfarin, new oral anticoagulants (NOACs) do not require regular blood monitoring. They have more predictable pharmacokinetics and pharmacodynamics and less drug and food interactions when compared with warfarin. In recent, randomized clinical trials; NOACs have been shown to be non-inferior to warfarin for the prevention of long-term stroke in patients with non-valvular $\mathrm{AF}^{8,9}$ Moreover, they are associated with a significantly lower rate of intracranial hemorrhagic events and favorable survival benefits. ${ }^{10}$ However, use of NOACs is dictated by the patient's renal function because a significant proportion of these drugs are excreted via the renal route. As renal function in elderly patients decreases, prescription of NOACs in the elderly, especially octogenarians, requires caution. ${ }^{11}$ The present study aimed to analyze the efficacy (prevention of stroke or systemic embolism) and safety (risk of bleeding) of NOACs prescribed in a Korean octogenarian population.

\section{Methods}

\section{Study Design and Subjects}

The medical records of 158 patients aged $\geq 80$ years and with non-valvular AF who started NOAC treatment for primary or secondary prevention of ischemic stroke or systemic embolism at the Asan Medical Center, Korea; between January, 2011 and September, 2014; were retrospectively reviewed. Non-valvular AF was defined as AF occurring in the absence of rheumatic mitral valve disease, a prosthetic heart valve, or mitral valve repair. ${ }^{11}$ The baseline characteristics of the enrolled study patients are presented in Table 1. The mean follow-up duration was $276 \pm 202$ days. The mean $\mathrm{CHA}_{2} \mathrm{DS}_{2}$-VASc score, a cumulative score of congestive heart failure, hypertension, age ( $\geq 75$ years or $\geq 65$ years), diabetes, stroke, vascular disease, and sex (female); was 4.7. Of the 158 patients who received NOACs, 54 (34.2\%) had received dabigatran ( 50 on a low dosage of $110 \mathrm{mg}$, twice daily; 4 on a normal dosage of $150 \mathrm{mg}$ twice daily) and 104 (65.2\%) received rivaroxaban (54 on a low dosage of $10-15 \mathrm{mg}$ daily; 50 on a normal dosage of $20 \mathrm{mg}$ daily). In order to evaluate renal function, estimated glomerular filtration rate (eGFR) obtained in the octogenarian population was compared with that obtained from a younger age group of subjects $(n=496)$ selected from the NOAC patient pool at the Asan Medical Center. This study was approved by the institutional review board of the Asan Medical Center.

\section{Outcome Assessments}

The efficacy outcome was the composite of ischemic stroke or systemic embolism. Stroke was defined as sudden onset of a focal neurological deficit lasting at least 24 hours. Systemic embolism was defined as acute vascular occlusion of an extremity or major organ as documented either at the time of autopsy or with angiography or vascular imaging.

The safety outcome was major bleeding. Major bleeding was defined as a decrease in hemoglobin levels $\geq 2 \mathrm{~g} / \mathrm{dL}$, transfusion of $\geq 2$ units of packed red blood cells, symptomatic intracranial hemorrhage, and death from bleeding.

Two investigators reviewed the patients' medical records during the follow-up period and adjudicated all stroke, systemic embolism, and bleeding events that contributed to these prespecified outcomes. Event rates were presented as the number of events per 100 patient-years of follow-up.

\section{Statistical Analysis}

Statistical analysis was performed using the SPSS software package (Version 21, SPSS Inc., Chicago, IL), and data were expressed as the mean $\pm \mathrm{SD}$ (continuous variables) or as frequency (categorical variables).

\section{Results}

\section{Renal Function in Octogenarians}

The renal function as measured by eGFR showed a left-shift in the octogenarian population when compared with that measured of the younger population (Figure 1). In the younger population, serum creatinine levels of $0.5-1.0 \mathrm{mg} / \mathrm{dL}$ indicated eGFR $>50$ $\mathrm{mL} / \mathrm{min}$; while in octogenarians, serum creatinine levels of 0.5-1.0 $\mathrm{mg} / \mathrm{dL}$ indicated moderately depressed $(50 \mathrm{~mL} / \mathrm{min}$ or below) eGFR in $51 \%$ of patients. Serum creatinine levels were influenced by medical illness or administered medications. Factors 
Table 1. Clinical characteristics of study patients

\begin{tabular}{ll}
\hline Demographics & \\
\hline Age (years) & $84.2 \pm 3.5 \mathrm{y}$, men $63(37.5 \%)$ \\
Body weight $(\mathrm{kg}) / \mathrm{SBP}(\mathrm{mmHg})$ & $58.5 \pm 11.3 / 131.7 \pm 22.7$ \\
Paroxysmal AF & $62(36.9 \%)$ \\
Creatinine (mg/dL) & $1.0 \pm 0.3$ \\
eGFR (mL/min/1.73 m²) & $48.0 \pm 14.0$ \\
CV risk factor & \\
\hline Prior stroke/TIA or systemic embolism & $84(50.0 \%)$ \\
Previous PCI/Previous Ml & $37(22.0 \%) / 8(4.8 \%)$ \\
CHF/HT/DM & $30(17.9 \%) / 118(70.2 \%) / 42(25.0 \%)$ \\
Treatment & \\
\hline Duration of NOACs use (days) & $275.8 \pm 201.8$ \\
Dose reduction & $105(66.2 \%)$ \\
Prior ASA use/Current ASA use & $79(47.0 \%) / 17(10.8 \%)$ \\
Prior warfarin use & $110(65.5 \%)$ \\
CHA 2 DS 2 -VASc & $4.8 \pm 1.4$ \\
HAS-BLED & $2.0 \pm 0.9$ \\
\hline
\end{tabular}

Values are expressed as the mean $\pm \mathrm{SD}$, median (interquartile range) or number (percentage).

Dose reduction refers to dabigatran $110 \mathrm{mg}$ bid, dabigatran 10 or $15 \mathrm{mg}$ qd.

AF, atrial fibrillation; ASA, acetylsalicylic acid; CHF, congestive heart failure; CV, cardiovascular; DM, diabetes mellitus; eGFR, estimated glomerular filtration rate; $\mathrm{HT}$, hypertension; MI, myocardial infarction; NOACs, new oral anticoagulants; $\mathrm{PCl}$, percutaneous coronary intervention; SBP, systolic blood pressure; TIA, transient ischemic stroke.

$\mathrm{CHA}_{2} \mathrm{DS} \mathrm{S}_{2}$-VASc is the cumulative score of congestive heart failure, hypertension, age ( $\geq 75$ years or $\geq 65$ years), diabetes, stroke, vascular disease, and sex (female).

HAS-BLED is the cumulative score of hypertension, abnormal renal and liver function, stroke, bleeding, labile INRs, elderly (age >65 years), and drugs or alcohol.

aggravating renal functions included trauma, hospitalization, dehydration, poor oral intake, administration of antibiotics, medical imaging, and more. An example of fluctuating renal function is illustrated in Figure 2.

\section{Efficacy of NOACs in the Octogenarian Population}

No systemic embolic events were observed during the follow-up period. Stroke occurred in 2 patients ( 1.16 events/100 patientyears). The clinical profiles of patients with ischemic stroke or bleeding are presented in Figure 3. One patient experienced ischemic stroke and showed a border zone infarction at the parieto-occipital region with simultaneous and significant narrowing of the carotid artery. Therefore, a clear cause of infarction was not clear when considering both cardioembolic and large artery disease. A patient with intracranial bleeding (subarachnoid hemorrhage) showed electrocardiographic features of tachycardia-bradycardia syndrome. The cause of the subarachnoid hemorrhage was not clear and may have been caused by either dabigatran or by trauma from a fall. 


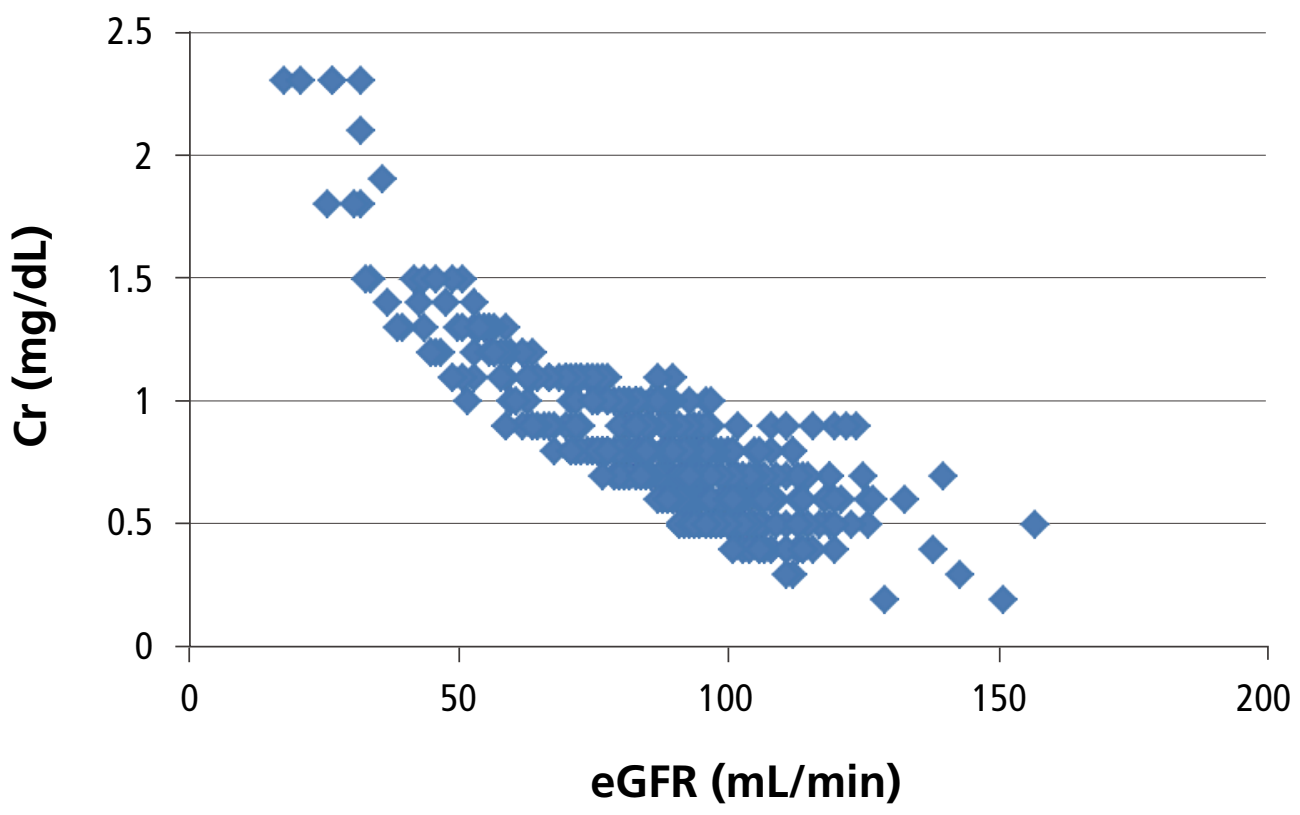

B

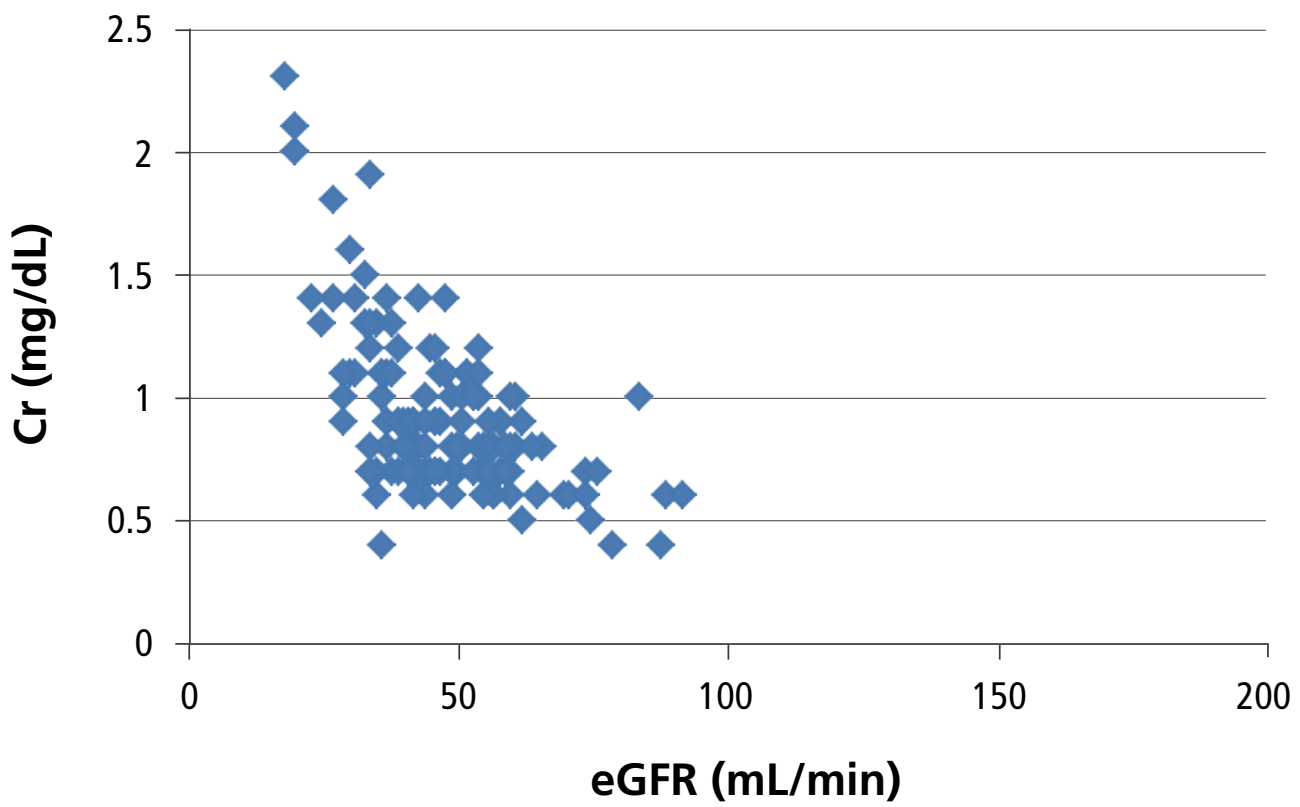

Figure 1. Plot of serum creatinine ( $\mathrm{Cr}$ ) vs. estimated glomerular filtration rate (eGFR).

The association of eGFR and creatinine levels from patients who were prescribed new oral anticoagulant is shown. Panel A depicts patients younger than 80 years, and $B$ depicts those 80 years or older. The curves are shifted to the left in the older patients group. eGFRs were higher than $50 \mathrm{~mL} / \mathrm{min}$ when serum creatinine levels were between 0.5 and $1.0 \mathrm{~mL} / \mathrm{min}$ in patients younger than 80 years, while eGFRs were below $50 \mathrm{~mL} / \mathrm{min}$ in approximately half (51\%) of octogenarian patients. 

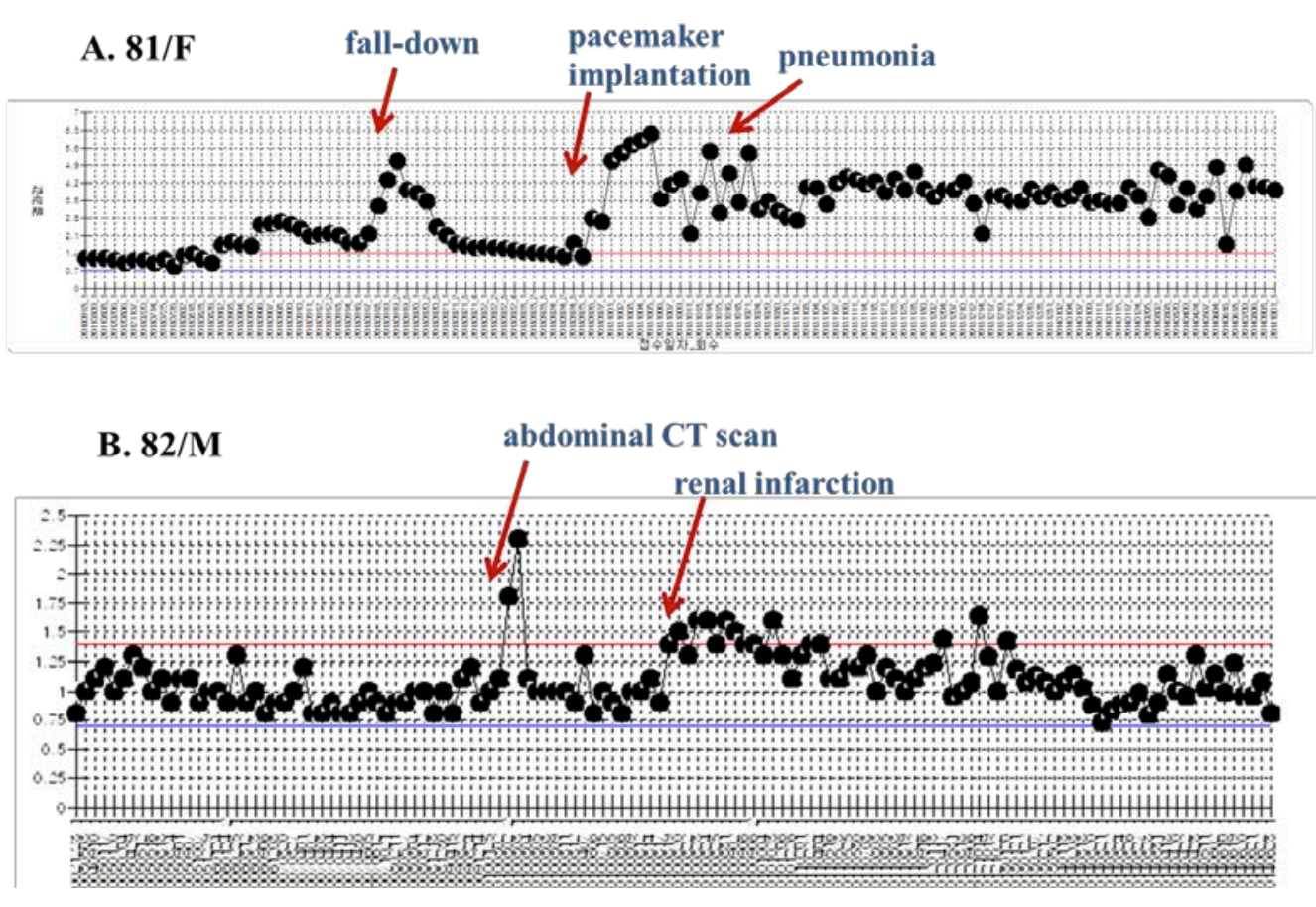

Figure 2. Temporal changes of serum creatinine levels in two octogenarian patients.

Serum creatinine levels were highly vulnerable and influenced by patients' medical conditions or other external factors. The two graphs show transient elevation of serum creatinine levels after infection, exposure to contrast dyes, or changes in other medical conditions in octogenarian patients.

\section{Safety of NOACs in the Octogenarian Population}

Clinically significant bleeding occurred in 13 patients (8.9\% per 100 patient-years). Gastrointestinal bleeding including anemia of unknown origin was the most common cause of major bleeding $(\mathrm{n}=7)$. Hematuria, intramuscular and intracranial bleeding occurred in 4,2 , and 1 patient, respectively. NOAC use was discontinued in $30(18.9 \%)$ patients, largely due to bleeding complications. Other side effects that required discontinuation of NOACs were dyspepsia, chest pain, fatigue, and increased creatinine (Figure 4).

\section{Discussion}

The major findings of the present study are as follows: (1) NOACs were effective for the prevention of stroke or systemic embolism in octogenarian patients; (2) NOACs were discontinued in $18.9 \%$ of patients and the major cause of discontinuation was bleeding complications; and (3) considering the high risk of bleeding while maintaining its efficacy, a systematic study aimed at determining the optimum dosage in an aged patient population is required.

Recent studies have investigated the effects of NOACs and consequently established their role in the field of stroke prevention in AF. In addition, sub-group analysis on the Asian population has reported even more improved results with the use of NOACs. The reported events rate of stroke or systemic embolism ranges between 1.26-2.6\%/year in patients on NOACs, and 2.61-3.4\%/year in patients on warfarin. ${ }^{12-14}$ Our study showed a similar efficacy profile of NOACs in the octogenarian population, confirming that NOACs may be non-inferior or more effective than warfarin for the prevention of embolic events in much older ( $\geq 80$ years) AF patients. Risk of major bleeding was reported to be 4.43-5.10/100 patient-years for NOACs and 4.37$4.40 / 100$ patient-years for warfarin in patients aged $\geq 75$ years. ${ }^{15,16}$ Although there have as yet been no reports on the risk of bleeding from NOACs in this extreme age group, the risk of major 
A

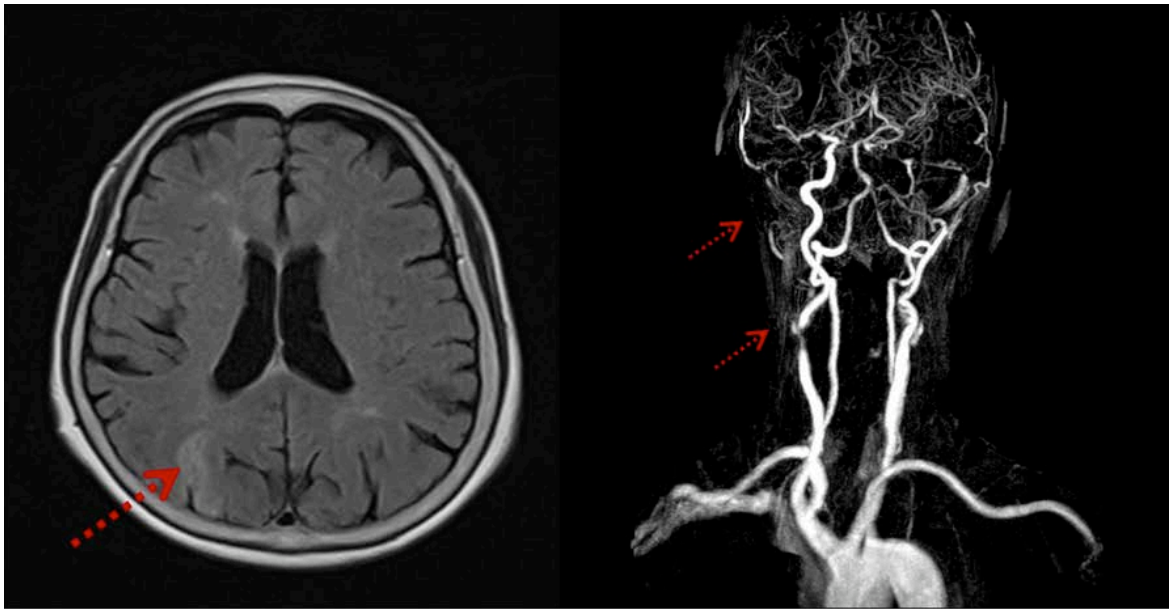

B

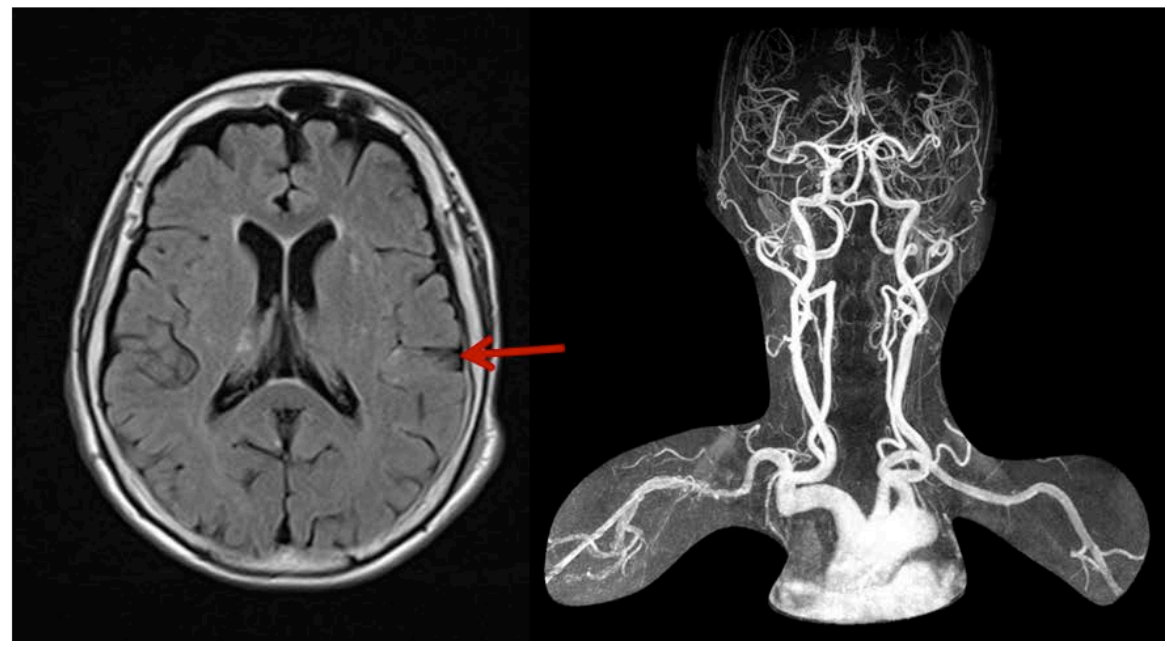

Figure 3. Magnetic resonance (MR) imaging of patients with ischemic stroke and intracranial hemorrhage.

A) An 84 year-old female patient visited the emergency room for left side weakness and gait disturbance. She had been diagnosed with hypertension and atrial fibrillation and had been prescribed rivaroxaban $10 \mathrm{mg}$ qd. Cerebral infarction involving a border zone of the right parieto-occipital junction was noted by MR imaging (large arrow, left panel). MR angiography showed a complete occlusion of the left internal carotid artery and severe concentric stenosis at the bulb portion of the right internal carotid artery (small arrows, right panel).

B) An 80 year-old female patient with hypertension and paroxysmal atrial fibrillation (AF) visited the emergency room for evaluation of syncope. She had been taking dabigatran $110 \mathrm{mg}$ bid. MR imaging showed curvilinear high signal intensity along the sulci in the left central sulci suggestive of minor subarachnoid hemorrhage (arrow, left panel). No significant steno-occlusive lesions in the intracranial or proximal neck vessels were found (right panel). The cause of syncope was sinus pause following termination of AF. A DDDR type permanent pacemaker was implanted.

bleeding (8.9/100 patient-years in our study) does not appear to be significantly different from that observed with the use of warfarin therapy (13.1/100 patient-years) and reported in previous studies of octogenarian patients. ${ }^{7}$ In addition, a recent prospective observational Italian study reported that the rate of major bleeding was low (1.87/100 patient-years) in octogenarians on warfarin. ${ }^{17}$ Thus, considering the reduced renal excretion capacity in an aged patient population and our own results regarding the risk of major bleedings in octogenarian patients, the currently recommended NOAC dosage may be higher than ideal. Future prospective randomized clinical trials in a larger number of patients are required to investigate optimum NOAC dosage this 


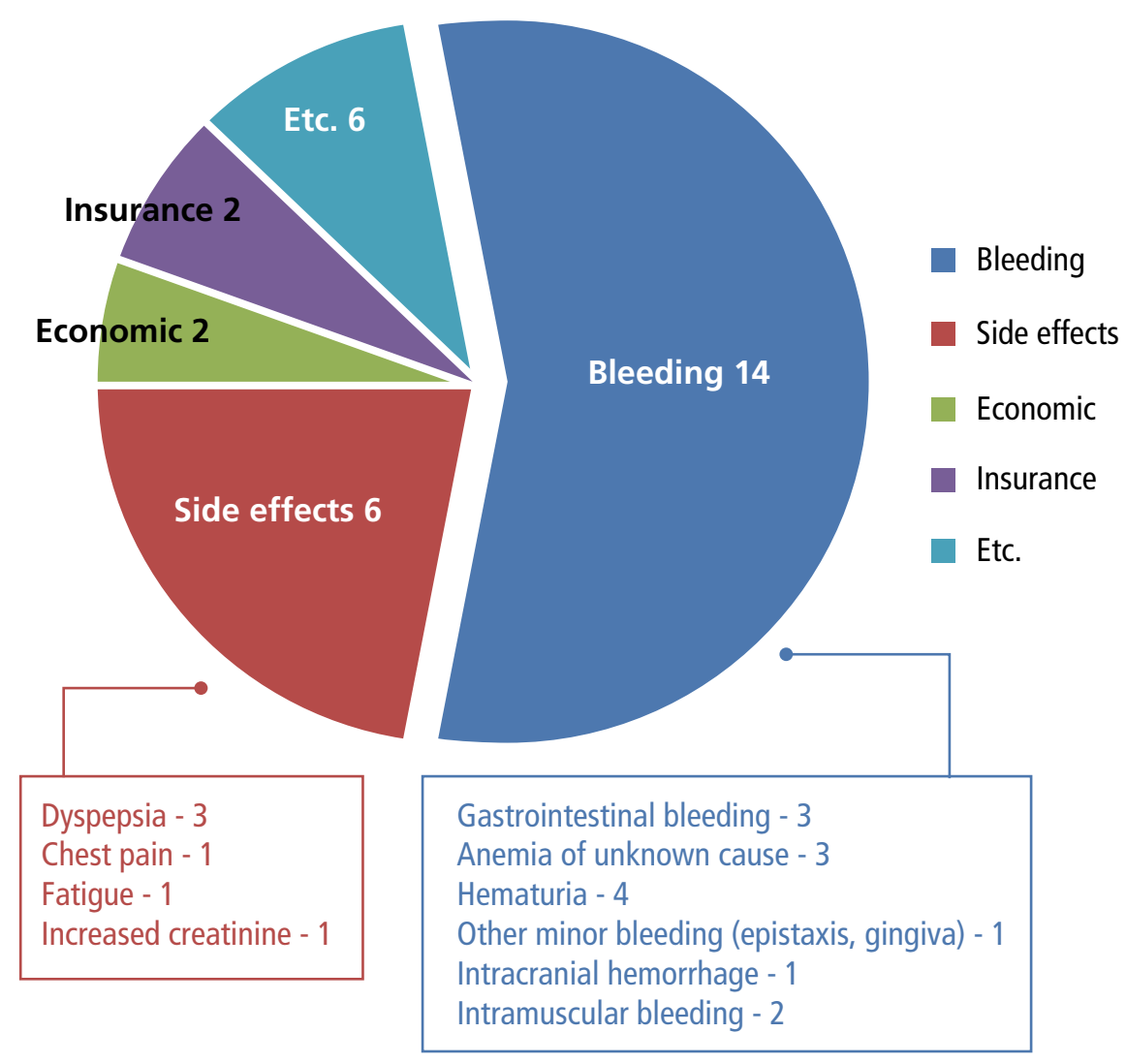

Figure 4. Causes for discontinuation of new oral anticoagulants.

extreme age group of patients. In the Randomized Evaluation of Long-Term Anticoagulation Therapy (RE-LY) trial, risks of stroke or systemic embolism were not found to be statistically different across doses of dabigatran $(110 \mathrm{mg}$ and $150 \mathrm{mg})$ in elderly patients aged $\geq 75$ years. ${ }^{15}$ In a Japanese trial using low dosage rivaroxaban (15 mg once daily; mean age of study population, 71 years), a strong trend towards a decreased rate of stroke or systemic embolism with low dose rivaroxaban vs. warfarin was observed $(\mathrm{HR}=0.49 ; p=0.050) .{ }^{12}$ Therefore, low dose NOAC administration may be non-inferior over normal doses for the prevention of stroke or systemic embolism in East Asian octogenarians. Moreover, low dose NOAC was significantly associated with a decreased risk of total or major bleeding when compared with normal dose NOAC. Based on these results, NOAC therapy, especially low dose use, may be noninferior or superior to warfarin for preventing total and major bleeding in frail patients such as octogenarians.

This study had several limitations. First, this was a retrospective analysis and the number of patients was relatively low. Second, different types and doses of NOACs were prescribed in our analysis. Thus, the efficacy and safety of different NOACs could not be compared. Despite these limitations, the present study shows that NOACs are highly effective for prevention of stroke or systemic embolism in the octogenarian population.

\section{Conclusions}

NOACs are highly effective for the prevention of stroke or systemic embolism in Korean octogenarian patients with nonvalvular AF. Risk of major bleeding with NOACs use was not uncommon. 
Table 2. Causes of bleeding

\begin{tabular}{|c|c|c|c|c|c|c|}
\hline $\begin{array}{l}\text { Age } \\
\text { (year) }\end{array}$ & Sex & Bleeding site & NOAC dose & HAS-BLED & Anti-platelet use & $\begin{array}{c}\text { eGFR } \\
\left(\mathrm{mL} / \mathrm{min} / 1.73 \mathrm{~m}^{2}\right)\end{array}$ \\
\hline 84 & $M$ & hematemesis & Xrt 10 & 1 & clopidogrel & 48 \\
\hline 83 & $M$ & melena & Prd 220 & 2 & - & 58 \\
\hline 88 & $\mathrm{~F}$ & melena & Xrt 10 & 1 & - & 50 \\
\hline 84 & $M$ & $\mathrm{Hg} 12$ to 10 & Xrt 10 & 1 & - & 38 \\
\hline 82 & $M$ & $\mathrm{Hg} 10$ to 7.4 & Xrt 10 & 1 & - & 106 \\
\hline 82 & $\mathrm{~F}$ & $\mathrm{Hg} 11$ to 5.0 & Xrt 20 & 2 & aspirin & 30 \\
\hline 80 & $\mathrm{~F}$ & $\mathrm{ICH}$ & Prd 220 & 3 & aspirin & 36 \\
\hline 82 & M & $\begin{array}{l}\text { thigh hematoma/hemoptysis } \\
\text { /hematuria/melena }\end{array}$ & Xrt 10 & 1 & - & 82 \\
\hline 85 & $\mathrm{M}$ & thigh hematoma & Prd 220 & & - & \\
\hline 89 & $\mathrm{~F}$ & hematuria & Xrt 10 & 1 & - & 67 \\
\hline 83 & M & hematuria & Prd 220 & 1 & - & 61 \\
\hline 91 & $M$ & hematuria & Xrt 15 & 4 & aspirin, clopidogrel & 27 \\
\hline 90 & $M$ & hematuria & Xrt 15 & 3 & - & 51 \\
\hline
\end{tabular}

eGFR, estimated glomerular filtration rate; F, female; $\mathrm{Hg}$, hemoglobin (g/dL); ICH, intracranial hemorrhage; M, male; NOACs, new oral anticoagulants; Prd 220, dabigatran $110 \mathrm{mg}$ bid; Xrt 10, rivaroxaban $10 \mathrm{mg}$ qd; Xrt 15, rivaroxaban $15 \mathrm{mg}$ qd; Xrt 20, rivaroxaban $20 \mathrm{mg}$ qd.

HAS-BLED is the cumulative score of hypertension, abnormal renal and liver function, stroke, bleeding, labile INRs, elderly (e.g., age >65 years), and drugs or alcohol.

\section{Disclosures}

The authors have no conflicts of interest to disclose.

\section{References}

1) Go AS, Hylek EM, Phillips KA, Chang Y, Henault LE, Selby JV, Singer DE. Prevalence of diagnosed atrial fibrillation in adults: national implications for rhythm management and stroke prevention: the AnTicoagulation and Risk Factors in Atrial Fibrillation (ATRIA) Study. JAMA. 2001;285:2370-2375.

2) Wolf PA, Abbott RD, Kannel WB. Atrial fibrillation as an independent risk factor for stroke: the Framingham Study. Stroke. 1991;22:983-988.

3) Kannel WB, Wolf PA, Benjamin EJ, Levy D. Prevalence, incidence, prognosis, and predisposing conditions for atrial fibrillation: population-based estimates. Am J Cardiol. 1998;82:2N-9N.

4) Hart RG, Pearce LA, Aguilar MI. Meta-analysis: antithrombotic therapy to prevent stroke in patients who have nonvalvular atrial fibrillation. Ann Intern Med. 2007;146:857-867.

5) Mant J, Hobbs FD, Fletcher K, Roalfe A, Fitzmaurice D, Lip GY, Murray E; BAFTA investigators; Midland Research Practices Network (MidReC). Warfarin versus aspirin for stroke prevention in an elderly community population with atrial fibrillation (the Birmingham Atrial Fibrillation Treatment of the Aged Study, BAFTA): a randomised controlled trial. Lancet. 2007;370:493-503.

6) Singer DE, Chang Y, Fang MC, Borowsky LH, Pomernacki NK, Udaltsova N, Go AS. The net clinical benefit of warfarin anticoagulation in atrial fibrillation. Ann Intern Med. 2009;151:297-305.

7) Hylek EM, Evans-Molina C, Shea C, Henault LE, Regan S. Major hemorrhage and tolerability of warfarin in the first year of therapy 
among elderly patients with atrial fibrillation. Circulation. 2007;115:2689-2696.

8) Connolly SJ, Ezekowitz MD, Yusuf S, Eikelboom J, Oldgren J, Parekh A, Pogue J,Reilly PA, Themeles E, Varrone J, Wang S, Alings M, Xavier D, Zhu J, Diaz R, Lewis BS, Darius H, Diener HC, Joyner CD, Wallentin L; RE-LY Steering Committee and Investigators. Dabigatran versus warfarin in patients with atrial fibrillation. NEngl J Med. 2009;361:1139-1151.

9) Patel MR, Mahaffey KW, Garg J, Pan G, Singer DE, Hacke W, Breithardt G, Halperin JL, Hankey GJ, Piccini JP, Becker RC, Nessel CC, Paolini JF, Berkowitz SD, Fox KA, Califf RM; ROCKET AF Investigators. Rivaroxaban versus warfarin in nonvalvular atrial fibrillation. N Engl J Med. 2011;365:883-891.

10) Sardar P, Chatterjee S, Chaudhari S, Lip GY. New oral anticoagulants in elderly adults: evidence from a meta-analysis of randomized trials. J Am Geriatr Soc. 2014;62:857-864.

11) January CT, Wann LS, Alpert JS, Calkins H, Cigarroa JE, Cleveland JC, Jr., Conti. JB, Ellinor PT, Ezekowitz MD, Murray KT, Sacco RL, Stevenson WG, Tchou PJ, Tracy CM, Yancy CW. 2014 AHA/ACC/HRS guideline for the management of patients with atrial fibrillation: executive summary: a report of the American College of Cardiology/American Heart Association Task Force on practice guidelines and the Heart Rhythm Society. Circulation. 2014;130:2071-2104.

12) Hori M, Matsumoto M, Tanahashi N, Momomura $S$, Uchiyama $S$, Goto S, Izumi T, Koretsune Y, Kajikawa M, Kato M, Ueda H, Iwamoto K, Tajiri M; J-ROCKET AF study investigators. Rivaroxaban vs. warfarin in Japanese patients with atrial fibrillation - the J-ROCKET AF study -. Circ J. 2012;76:2104-2111.

13) Hori M, Connolly SJ, Zhu J, Liu LS, Lau CP, Pais P, Xavier D, Kim SS, Omar R, Dans AL, Tan RS, Chen JH, Tanomsup S, Watanabe M, Koyanagi M, Ezekowitz MD, Reilly PA, Wallentin L, Yusuf S; RE-LY Investigators. Dabigatran versus warfarin: effects on ischemic and hemorrhagic strokes and bleeding in Asians and non-Asians with atrial fibrillation. Stroke. 2013;44:1891-1896.

14) Wong KS, Hu DY, Oomman A, Tan RS, Patel MR, Singer DE, Breithardt G, Mahaffey KW, Becker RC, Califf R, Fox KA, Berkowitz SD, Hacke W, Hankey GJ; Executive Steering Committee and the ROCKET AF Study Investigators. Rivaroxaban for stroke prevention in East Asian patients from the ROCKET AF trial. Stroke. 2014;45:1739-1747.
15) Eikelboom JW, Wallentin L, Connolly SJ, Ezekowitz M, Healey JS, Oldgren J, Yang S, Alings M, Kaatz S, Hohnloser SH, Diener HC, Franzosi MG, Huber K, Reilly P, Varrone J, Yusuf S. Risk of bleeding with 2 doses of dabigatran compared with warfarin in older and younger patients with atrial fibrillation: an analysis of the randomized evaluation of long-term anticoagulant therapy (RELY) trial. Circulation. 2011;123:2363-2372.

16) Halperin JL, Hankey GJ, Wojdyla DM, Piccini JP, Lokhnygina Y, Patel MR, Breithardt G, Singer DE, Becker RC, Hacke W, Paolini JF, Nessel CC, Mahaffey KW, Califf RM, Fox KA; ROCKET AF Steering Committee and Investigators. Efficacy and safety of rivaroxaban compared with warfarin among elderly patients with nonvalvular atrial fibrillation in the Rivaroxaban Once Daily, Oral, Direct Factor Xa Inhibition Compared With Vitamin K Antagonism for Prevention of Stroke and Embolism Trial in Atrial Fibrillation (ROCKET AF). Circulation. 2014;130:138-146.

17) Poli D, Antonucci E, Testa S, Tosetto A, Ageno W, Palareti G; Italian Federation of Anticoagulation Clinics. Bleeding risk in very old patients on vitamin $\mathrm{K}$ antagonist treatment: results of a prospective collaborative study on elderly patients followed by Italian Centres for Anticoagulation. Circulation. 2011;124:824829 . 